\title{
Pregnancy with Myelomeningocele Foetus: A Case Study
}

\author{
Kharde SN*, Bhat AV and Sawant P \\ Department of OBG Nursing, Academy of Higher Education and Research (KAHER) Institute of Nursing Sciences, Karnataka, India
}

Received: December 11, 2017; Published: December 21, 2017

*Corresponding author: Kharde SN, Department of OBG Nursing, KLE Academy of Higher Education and Research (KAHER) Institute of Nursing Sciences, Nehru Nagar, Belagavi, Karnataka, India

\begin{abstract}
Foetus with Neural tube defect especially meningomyelocele is a rare condition. We report a case of twenty weeks Pregnancy with meningomyelocele admitted to labour room for termination. The diagnosis was confirmed with ultrasonography. History suggested that patient had previous abortion for anencephaly foetus, noncompliance to folic acid supplements and irregular follow-up. It is concluded that prenatal counselling, adherence to folic acid supplement and regular follow-up can prevent the further complication
\end{abstract}

Keywords: Spina Bifida; Meningomyelocele; Ultrasonography; Prenatal Counselling; Congenital Malformation

\section{Introduction}

Neural tube defects are the congenital malformation of the CNS resulting from defective closure of the neural tube during early embryogenesis between $3^{\text {rd }}$ and $4^{\text {th }}$ week of intrauterine life. It involves defect in the skull, vertebral column, the spinal cord and other portion of CNS. It occurs about 1 to 5 per 1000 live births. Risk in second siblings is high. The exact cause is not known, but the triggering factors are maternal radiation exposures, anticonvulsive drugs, exposure to chemicals, folic acid deficiency and genetic determinant [1]. The most common neural tube defect is Spina bifida contributing one in 1000 births. Spina bifida is the congenital defect of the spinal column due to failure of the fusion of vertebral arches with or without protrusion of the meninges and dysplasia of the spinal cord [1]. It is classified as spina bifida occulta and spina bifida cystica. Myelomeningocele is most common and severe form of spina bifida cystica, characterized by protrusion of spinal cord through the open vertebrae into the amniotic fluid. The severity of disability varies in accordance to the neurological and extent of intracranial abnormalities. The malformation is associated significant lifelong disability including motor and sensory deficits, neurogenic bowel and bladder, hind brain herniation and associated hydrocephalus, orthopaedics abnormality and cognitive deficits [2].

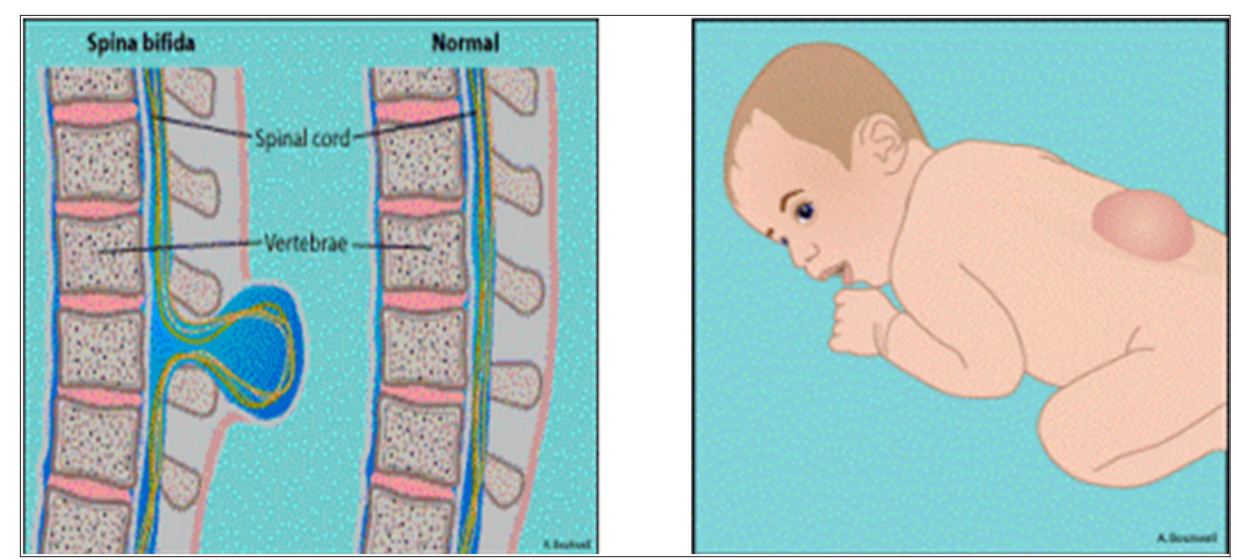

Figure 1: Induction of labour was started as per prostaglandin regimen. She delivered dead male foetus weighing about 520 gms.

\section{Case Report}

We report a case of 25years old multigravida woman with 5 months of amenorrhea with meningomyelocele foetus admitted to labour room for termination. Her history says that she has 6 years of marital life and it was nonconsanguineous marriage. There was history of use of oral contraception for four years after marriage. Regarding her obstetrical history, she underwent induced abortion one and half year back as she was diagnosed as anencephalic foetus 
at 12 weeks. The patient given a history of regular menses. After one year of her induced abortion she again conceived naturally. Ultrasonography was done at 8weeks in which no abnormality was detected. After this she was not regular for her follow up. But at 20weeks she visited OPD for follow up, USG was done and report showed Lumbosacral Meningomyelocele measuring $1.76 \mathrm{~cm}$ and $0.85 \mathrm{~cm}$. According to patient she was not taking the folic acid supplements due to the side effects. Genetic counselling was given to her and her husband and was advised for termination of pregnancy. Induction of labour was started as per prostaglandin regimen. She delivered dead male foetus weighing about 520gms. Mother was counselled for pre conceptional care and regular follow up in future (Figure 1).

\section{Discussion}

Meningomyelocele results in injury of spinal cord tissues and requires lifelong support and rehabilitation. If neural tube defects occurred in a woman's previous pregnancy, increased antepartum foetal surveillance is required for the current pregnancy [3]. This surveillance should include consultation with a geneticist and targeted foetal ultrasonography to assess the foetal spine and cranium. In addition, preconception supplementation with folic acid at $4 \mathrm{mg} /$ day is recommended; this dosage is higher than that advised for a woman without such a history. A recent RCT named management of Meningomyelocele showed that prenatal correction by fetoscopic or open surgery resulted in improved neurological outcomes. Prenatal meningomyelocele surgery is a complex surgical procedure that requires an experienced multidisciplinary team with dual focus on both the mother and the foetus. Despite of confirmed benefits there is a chance of PPROM, Oligohydramnios, Uterine Dehiscence and preterm labour are the challenging out comes [4]. Neurological defects in foetus occur due to many reasons. The identified cause in present case is deficiency of folic acid and history of pregnancy with anencephaly. Women planning to become pregnant should avoid all alcohol consumption, smoking, and use of illegal drugs before and during the pregnancy, because these activities may have serious deleterious effects on the foetus. It is also advisable for the prescribing provider to review all medications and supplements the woman is taking to assess for possible teratogenicity.

\section{Conclusion}

All women of childbearing potential should be receiving folic acid at a dosage of $0.4 \mathrm{mg} /$ day, in accordance with the recommendation of the US Center for Disease Control and Prevention (CDC). In this case if patient had come for regular check-up and taken folic acid regularly this incidence could be prevented. This is very important to stress on folic acid supplementation and regular follow up in antenatal advice.

\section{References}

1. Datta Parul (2018) Pediatric Nursing. ( $4^{\text {th }}$ edn) Jaypee Brothers Medical Publishers (P) LTD, New Delhi, India, pp. 352-353.

2. Antiel RM, Adzick NS, Thom EA, Burrows PK, Farmer DL, et al. (2016) Impact On Family And Parental Stress Of Prenatal Vs Postnatal Repair Of Myelomeningocele. American Journal Of Obstetric Gynaecology 215(4): 522 .

3. Pedreira DA, Zanon N, Nishikuni K, Moreira De Sá RA, Acacio GL, et al. (2016) Endoscopic Surgery For Antenatal Treatment Of Myelomeningocele. American Journal Of Obstetric Gynaecology 214(1): 111.

4. Johnson MP, Bennett KA, Rand L, Burrows PK, Thom EA, et al. (2016) The Management Of Myelomeningocele Study: Obstetrical Complications Following Prenatal Surgery. American Journal Of Obstetric Gynaecology 215(6): 778.

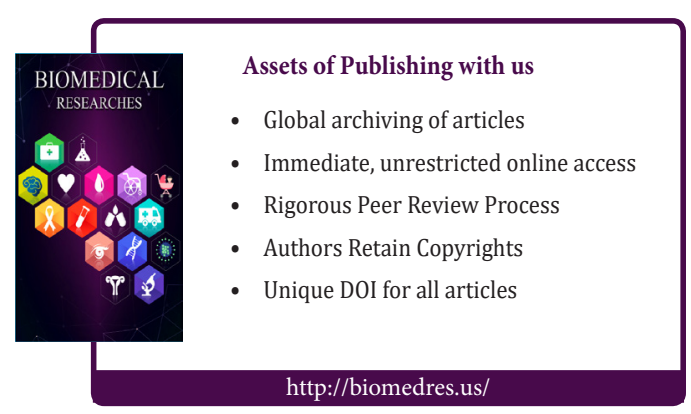

